\title{
XIX. On a simple rheostat
}

\section{G.F.C. Searle M.A.}

To cite this article: G.F.C. Searle M.A. (1903) XIX. On a simple rheostat, Philosophical Magazine Series 6, 6:31, 173-175, DOI: 10.1080/14786440309463000

To link to this article: http://dx.doi.org/10.1080/14786440309463000

$$
\text { 册 Published online: } 15 \text { Apr } 2009 .
$$

Submit your article to this journal

Џll Article views: 2

Q View related articles $₫$ 
The correction for stretching is

$$
\begin{gathered}
\frac{w c^{2}}{\mathrm{E} \alpha} \sinh \theta=\frac{w s \cdot c}{\mathrm{E} \alpha} \\
=\text { weight of chain } \times \frac{c}{\mathrm{E} \alpha} .
\end{gathered}
$$

For the ten-chain steel tape the correction is

$$
\begin{gathered}
\frac{\cdot 0005653 \times 7920 \times 3960 \times 8 \times 60}{\cdot 1617 \times 3 \times 10^{7}} \\
=1.757 \text { inches. }
\end{gathered}
$$

For the ten-chain circular wire (Jädern's) the correction is

$$
\begin{gathered}
\frac{\cdot 04 \times 2 \times(3960)^{2} \times 2 \cdot 2046}{39 \cdot 37 \times 8190 \times 3 \times 10^{7} \times 3 \cdot 1416 \times(1.33 \times 0.3937)^{2}} \\
=0.33182 \text { inch. }
\end{gathered}
$$

In any case the correction depends on the area of the crosssection of the wire, but not on its form.

XIX. On a Simple Rheostat. By G. F. C. Searle, M.A., University Lecturer in Physics,. Demonstrator in Experimental Physics, Cavendish Laboratory, Cambridge*.

1. N many electrical experiments it is necessary to adjust I the electric current flowing in a circuit to some definite value, and this is most easily done by varying the resistance of the circuit. But for accurate adjustment the resistance must be capable of continuous variation, and not merely of variation in steps, as is the case with a resistancebox. This continuous variation of the resistance is generally brought about by making a gradual alteration in the length of a piece of german-silver or platinoid wire included in the circuit, and the object of the present communication is to describe a rheostat in which the alteration is secured in a simple and effective manner.

The figure shows the general appearance of the rheostat. At the top of an upright there is a wooden wheel with a Vgroove in its edge, the wheel turning about a horizontal axis, while at the foot of the upright there is a $\mathbf{U}$-tube of glass containing a little mercury. The total length of the $U$-tube is about $30 \mathrm{cms}$. and the internal diameter of the tube is about $\cdot 8 \mathrm{~cm}$. An endless band about $165 \mathrm{cms}$. in length, which passes over the wheel and through the $\mathbf{U}$-tube,

* Communicated by the Author. 
is made up mainly of a piece of platinoid wire 015 inch $(\cdot 038 \mathrm{~cm}$.$) in diameter. One end of the platinoid wire is$ soldered to one end of a piece of thin "flexible" stranded wire $\mathrm{L}$, while at the other end of the platinoid wire a small eye is formed. To complete the band, one end of a piece of silk cord is lashed to the flexible wire near the soldered joint, and the other end of the cord is tied to the eye at the end of the platinoid wire. By means of the device described below, the endless band is kept tight enough to cause the wheel to grip the band sufficiently firmly to ensure that the band shall not slip in the groove when the wheel is turned. Then, by turning the wheel, the length of the platinoid wire included between the surface of the mercury in the right limb of the $\mathbf{U}$-tube and the end of the flexible wire can be varied from practically zero to about $165 \mathrm{cms}$., the consequent change in resistance being about 6 ohms. The other end of the flexible wire $\mathrm{L}$ is attached to a terminal screw $\mathrm{T}$, and $\mathrm{L}$ is long enough to enable the joint to pass freely over the wheel.

A second metallic connexion with the platinoid wire is obtained by a copper electrode, which dips into the mercury in the left limb of the $\mathbf{U}$-tube. This electrode is made in the shape of a narrow strip of sheet copper with a wider end, like a spade. The wide part is bent round so as to form a

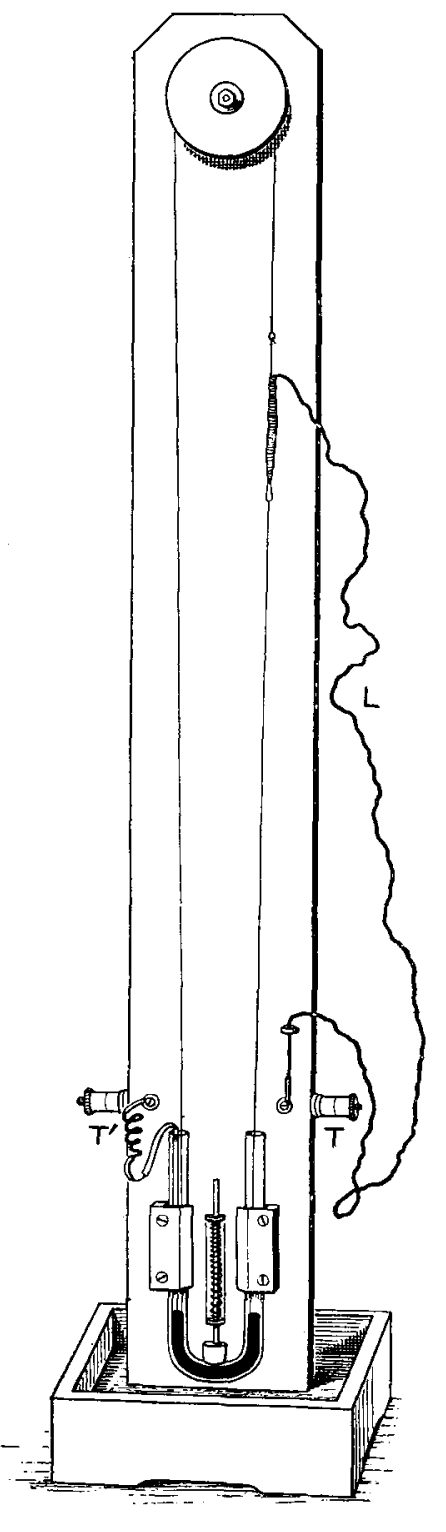
nearly complete cylinder, which just fits into the glass tube, 
and the cylindrical part is amalgamated. This electrode is connected by a short piece of flexible wire with a terminal screw $\mathrm{T}^{\prime}$.

The object of making the effective part of the platinoid wire to enter the $\mathbf{U}$-tube by the right limb and the copper electrode to dip into the left limb, is to avoid the accidental contacts between the platinoid wire and the part of the copper electrode above the surface of the mercury, which I found occurred when the electrode dipped into the right limb.

The radius of the wheel is somewhat greater than the radius of the bend of the $\mathbf{U}$-tube, in order that the wire may not be in contact with the glass at the level of the surface of the mercury.

Since the joint in the endless band is thicker than the rest of the band, it is necessary, in order to allow the joint to pass easily over the wheel, to give the $U$-tube a little play in a vertical direction. The tube, therefore, slides quite freely through some simple wooden guides, and the requisite tension is given to the band by a plunger, which presses upon the bend of the $\mathrm{U}$-tube and is actuated by a small coiled spring. The tube can thus rise slightly when the joint passes over the wheel, and the wire is always kept sufficiently tight and is never over-strained.

A rim $2 \frac{1}{2} \mathrm{cms}$. high round the base board forms a trough, which catches the few small globules of mercury which are carried up by the wire and are sometimes shaken off it.

The resistance of the rheostat in a given position of the wire is very definite, and violent tapping or shaking has no effect upon it.

As mercury attacks solder, care must be taken not to wind the joint into the mercury. I find that the mercury also attacks german-silver so rapidly that a german-silver wire completely loses its strength after a few minutes' immersion in the mercury. On the other hand, so far as I can judge by three months' experience, platinoid wire is quite unaffected by the mercury.

Since the wire must be quite flexible if it is to draw easily round the bend of the $U$-tube, its thickness is limited, and bence this type of rheostat is not adapted for use with large currents. Yet a platinoid wire 015 inch in diameter will carry 2 amperes without undue heating, and the heating leads to no inconvenience, for the wire, being exposed to the air, takes up almost instantly a steady temperature corresponding to the current passing through it.

The figure represents a specimen of the rheostat made for me by Messrs. W. G. Pye and Co., to whom I am indebted for some help in the details of the design. 